Vietnam Journal of Mechanics, VAST, Vol. 28, No. 2 (2006), pp. 94-102

\title{
SOME RESULTS OF COMPARISON BETWEEN NUMERICAL AND ANALYTIC SOLUTIONS OF THE ONE-LINE MODEL FOR SHORELINE CHANGE
}

\author{
LE XUAN HOAN \\ Institute of Mechanics, VAST, 264 Doi Can, Hanoi, Vietnam
}

\begin{abstract}
A qualitative understanding of the basic properties of complicated physical phenomena can often be obtained through the study of analytic solutions derived from simplified problems. Analytic solutions of shoreline change model for simple shoreline configurations are derived under idealized wave conditions. Both analytic and numerical methods are based on the one-line theory of shoreline change. In this paper some results of comparison of the numerical with analytic solutions are presented.
\end{abstract}

\section{INTRODUCTION}

Under certain idealized wave conditions and simple shoreline configurations, the equations of one-line theory of shoreline change can be reduced to the one-dimensional equation of heat diffusion type, which in some certain simplified cases can be solved analytically. The analytic solutions are often valuable for giving qualitative insights and investigating the properties of shoreline change. However, it is important to be aware of the limitations of analytic solutions and errors introduced by these limitations. For the real situation, the use of numerical model of shoreline change could be more appropriate.

Several authors have presented analytic solutions for certain simplified conditions (e.g. Bakker and Edelman 1965; Bakker 1969; Le Mehaute' and Soldate 1977; Walton and Chiu 1979; Larson, Hanson, and Kraus 1987). In order to describe more realistic situations involving general shoreline configurations, together with time varying wave conditions, the one-line theory has been developed using numerical solution techniques (e.g. Price, Tomlinson, and Willis 1973; Sasaki and Sakuramoto 1978; Kraus, Hanson, and Harikai 1985; Hanson and Kraus 1987). Four examples of shoreline evolution for simplified configuration using the analytical solution (A) and the numerical formulation $(\mathrm{N})$ are examined and presented in this paper.

\section{ONE-LINE THEORY FUNDAMENTALS}

The aim of one-line theory is to describe long-term variation of shoreline positions. Short-term variation (e.g, changes caused by storms or by rip currents) are regarded as negligible perturbations superimposed on the main trend of shoreline evolution. The fundamental assumption of this theory is that erosion or accretion of a beach results in a pure translation of beach profile. Thus, the bottom profile moves in parallel to itself without changing shape.

The major assumption of the theory is that the longshore sand transport takes place uniformly over the beach profile down to a certain limiting depth called the depth of closure, $\mathrm{D}_{C}$. Thus, beyond this depth the bottom does not move.

Following the above assumptions, mass conservation of sand along an infinitely small length $\Delta \mathrm{x}$ of the shoreline can be formulated as (see Fig. 1)[1]: 


$$
\frac{\partial y}{\partial t}+\frac{1}{\left(D_{C}+D_{B}\right)}\left[\frac{\partial Q}{\partial x}+q\right]=0
$$

where $x$ is the longshore coordinate $(\mathrm{m}) ; y$ is the shoreline position $(\mathrm{m})$ and perpendicular to $x$-coordinate; $t$ is the time $(\mathrm{s}) ; Q$ is the longshore sand transport rate $\left(\mathrm{m}^{3} / \mathrm{s}\right) ; \mathrm{D}_{B}$ is the average berm height $(\mathrm{m})$; and $q$ represents line sources and/or sinks along the coast $\left(\mathrm{m}^{3} / \mathrm{s} / \mathrm{m}\right)$.

In order to solve equation (2.1), it is necessary to specify an expression for the longshore sand transport rate, $Q$. This quantity is considered to be generated by wave obliquely incident to the shoreline. This relationship is taken to be [2]:

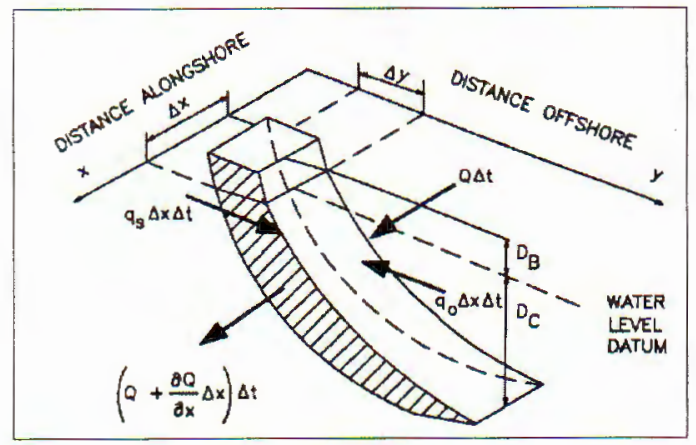

Fig. 1. Definition sketch for shoreline change calculation

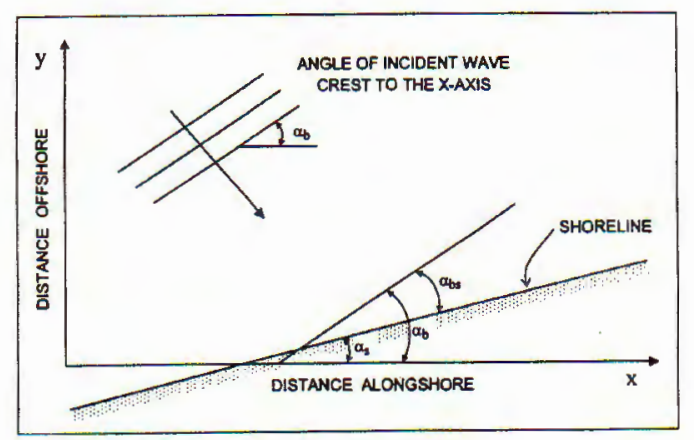

Fig. 2. Definition of breaking wave angle

$$
Q=Q_{0} \sin \left(2 \alpha_{b s}\right)
$$

where $\alpha_{b s}$ is the angle between breaking wave crest and the local shoreline and $Q_{0}$ is the amplitude of the longshore sand transport rate. The empirical predictive formula for the amplitude of the longshore sand transport rate is taken to be [2]:

$$
Q_{0}=\left(H^{2} C_{g}\right) \frac{K}{16\left(\frac{\rho_{s}}{\rho}-1\right)(1-p) 1.416^{\frac{5}{2}}},
$$

where $H$ is the significant breaking wave height $(\mathrm{m}) ; C_{g}$ is the wave group velocity at breaking point $(\mathrm{m} / \mathrm{s}) ; K$ is the empirical coefficient treated as a calibration parameter; $\rho_{s}$ is the density of sand $\left(\mathrm{kg} / \mathrm{m}^{3}\right) ; \rho$ is the density of water $\left(\mathrm{kg} / \mathrm{m}^{3}\right) ; p$ is the porosity of sand on the bed.

The breaking wave angle, $\alpha_{b s}$, may be expressed as (see Fig. 2):

$$
\alpha_{b s}=\alpha_{b}-\alpha_{s}=\alpha_{b}-\tan ^{-1}\left(\frac{\partial y}{\partial x}\right)
$$

where $\alpha_{b}$ is the angle between breaking wave crests and the $x$-axis; $\alpha_{s}$ is the angle between the shoreline and the $x$-axis. 


\section{ANALYTIC SOLUTION TECHNIQUE (A)}

For beaches with mild slope, it can be assumed that the breaking wave angle to the shoreline is small. In this case, $\sin \left(2 \alpha_{b s}\right) \approx 2 \alpha_{b s}$. If also the angle between the shoreline and the $x$-axis, is assumed to be small. In accordance with equation (2.4), $\alpha_{b s} \approx \alpha_{b}-\partial y / \partial x$, since the inverse tangent can be replaced by its argument if the argument is small. In this case the equation (2.2) can be rewritten as:

$$
Q=2 Q_{0}\left(\alpha_{b}-\frac{\partial y}{\partial x}\right) .
$$

If the amplitude of the longshore sand transport rate $Q_{0}$ as well as the breaking wave angle $\alpha_{b}$ is assumed independent of $x$ and $t$, and with negligible contributions from sources or sinks $(q=0)$, equations (2.1) and (3.1) can be rewritten as:

$$
\frac{\partial y}{\partial t}=\varepsilon \frac{\partial^{2} y}{\partial x^{2}},
$$

where $\varepsilon$ is a diffusion coefficient

$$
\varepsilon=\frac{2 Q_{0}}{\left(D_{C}+D_{B}\right)} .
$$

Equation (3.2) is analogous to the one-dimensional heat diffusion equation, it can be solved analytically for various initial and boundary conditions.

\section{NUMERICAL SOLUTION TECHNIQUE (N)}

Solving equations (2.1)-(2.4) numerically, we are no longer constrained by small angle assumption, making possible the solution of a wider variety of shore/structure configuration and a more realistic wave climate.

Equations (2.1)-(2.4) are discretized on a staggered grid, in which shoreline positions $y_{i}$ are defined at the centre of the grid cells and transport rates $Q_{i}$ at the cell walls. The Crank-Nicholson implicit scheme is used. The derivative $\partial Q / \partial x$ at each grid point is expressed as an equally weighted average between the present and the next time steps [3]:

$$
\frac{\partial Q_{i}}{\partial x}=\frac{1}{2}\left[\frac{Q_{i+1}^{\prime}-Q_{i}^{\prime}}{\Delta x}+\frac{Q_{i+1}-Q_{i}}{\Delta x}\right],
$$

where the prime $(I)$ is used to denote a quantity at the new time level, whereas the unprimed quantity indicates a value at the present time step, which is known.

Substituting equation (4.1) into equation (2.1) and linearizing of the wave angle in equation (2.2) in term of $\partial y / \partial x$ results in two systems of couple equations for the unknowns $y_{i}^{\prime}$ and $Q_{i}^{\prime}$ :

$$
\begin{gathered}
y_{i}^{\prime}=B^{\prime}\left(Q_{i}^{\prime}-Q_{i+1}^{\prime}\right)+y c_{i}, \\
Q_{i}^{\prime}=E_{i}\left(y_{i+1}^{\prime}-y_{i}^{\prime}\right)+F_{i},
\end{gathered}
$$

where $B^{\prime}=\Delta t / 2\left(D_{B}+D_{C}\right) \Delta x, y c_{i}$ is the function of known quantities, including $Q_{i}, q_{i}$ and $y_{i} . F_{i}$ and $E_{i}$ are the functions of wave height, wave angle, and other known quantities. 
Substituting (4.2) into (4.3) results in three-diagonal linear equation system and it is solved by the Thomas algorithm:

$$
-F_{i} Q_{i-1}^{\prime}+A_{i} Q_{i}^{\prime}-F_{i} Q_{i+1}^{\prime}=G_{i}
$$

where $A_{i}=2 F_{i}-\frac{\Delta x}{B^{\prime}}$ and $G_{i}=\frac{\Delta x}{B^{\prime}}\left[\frac{y_{i+1}-y_{i}}{\Delta x} F_{i}-E_{i}-\frac{F_{i}}{\Delta x}\left(y c_{i}-y c_{i-1}\right)\right]$.

The initial condition is taken to be $y_{i}=y_{\left(x_{i}, 0\right)}$ where $y_{\left(x_{i}, 0\right)}$ is the initial shoreline position.

The most commonly used boundary condition at both lateral boundaries is $\partial Q / \partial x=$ $0[1]$. For equation (2.1), if $\partial Q / \partial x=0$ at the boundaries and with negligible sources or sinks, then $\partial y / \partial t=0$, indicating that y does not change with time. The above boundaries should be located far away from a project to assure that the conditions in the vicinity of the boundary are unaffected by changes that take place in the project.

The numerical stabilily of the calculation scheme is governed by stability parameter:

$$
R_{S}=\frac{\varepsilon \Delta t}{(\Delta x)^{2}}
$$

Kraus and Harikai showed that the numerical accuracy of the solution depends on the value of $R_{S}$. For the implicit sheme, the values of $R_{S}$ less than 0.26 are suggested [3].

\section{SIMULATIONS}

In order to investigate the agreement between the numerical and the analytic solutions, the breaking wave height, $H_{b}$, the wave group velocity at breaking point, $C_{g}$, and the breaking wave angle, $\alpha_{b}$, are held constant $\left(H_{b}=1.0 \mathrm{~m}, \mathrm{C}_{g}=4.0 \mathrm{~m} / \mathrm{s}\right)$, in which the breaking wave angle is taken a small value ( $\alpha_{b}=5$ degrees) to satisfy the assumption of small angle in equation (3.1). In addition, in order to estimate the differences between analytic and numerical solutions in case of larger breaking wave angle, the numerical model was applied for two values of breaking wave angle ( $\alpha_{b}=15$ and 30 degrees). In all cases, the total calculation time was an year.

Relative errors (\%) between numerical $\left(R_{i}^{N}\right)$ and analytic $\left(R_{i}^{A}\right)$ solutions at computed point $i$ are calculated as follow:

$$
E R R_{i}=\frac{\left|R_{i}^{N}-R_{i}^{A}\right|}{R_{i}^{A}} 100
$$

where $R_{i}$ is the shoreline position at point $i$.

The other parameters were used for simulating here: the empirical coefficient, $K=0.77$, the depth of closure, $D_{C}=4 \mathrm{~m}$, average berm height, $D_{B}=1 \mathrm{~m}$.

\subsection{Rectangle-shaped beach fill}

A beach fill (or a natural cape) shape is treated by approximating its shape with a rectangle. The initially distance from the outer side of the rectangle to the local shoreline is taken $y=y_{0}$ (see Fig. 3). The analytic solution describing the shoreline positions is [4]

$$
y_{(x, t)}=\sum_{n=1}^{\infty} a_{n} \exp \left[-\left(\frac{n \pi a}{L}\right)^{2} t\right] \sin \frac{n \pi a}{L} x,
$$




$$
a_{n}=\frac{2}{L} \int_{L_{1}}^{L_{2}} y_{0} \sin \frac{n \pi x}{L} d x, \quad n=1,2,3, \ldots
$$

where $L$ is the beach length, $L_{1}, L_{2}$ are the positions of the initial beach fill on the x-axis.

The shoreline calculated by analytic solution (5.2) is shown as line 1 in Fig. 3. The shorelines obtained by numerical method are shown as line 2,3 , and 4, corresponding to breaking wave angles 5,15 , and 30 degrees, respectively. The line number 0 shows the initial shoreline.

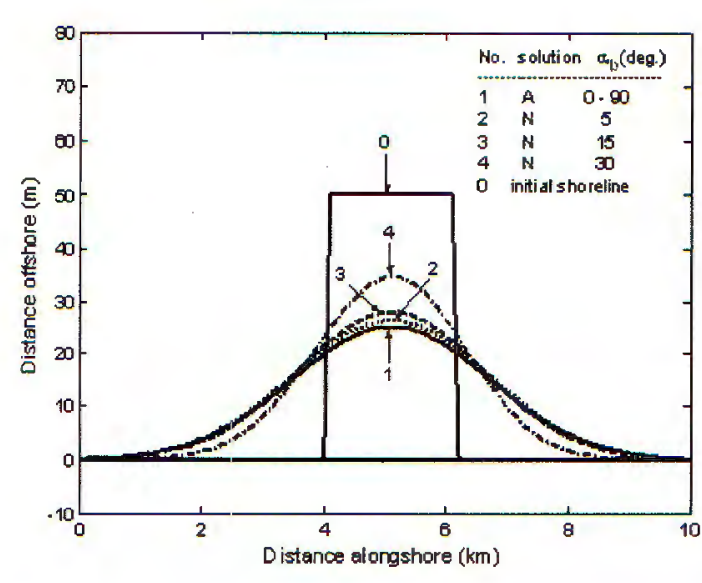

Fig. 3. Spreading of a rectangle-sharped beach fill

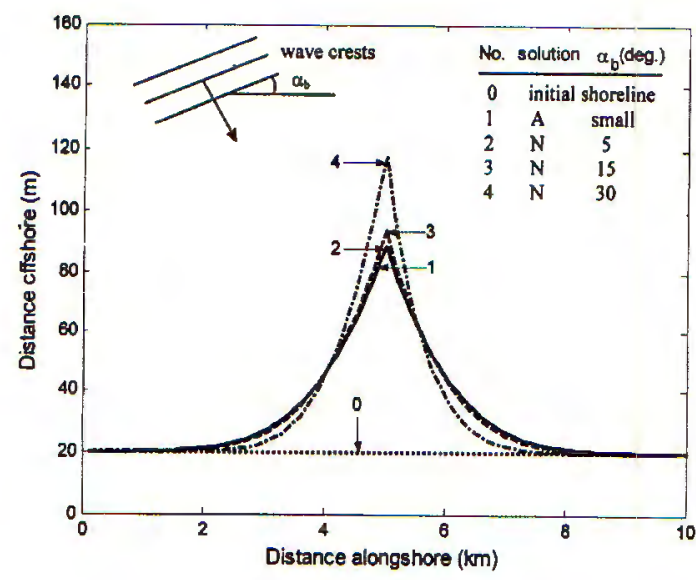

Fig. 4. Delta evolution caused by discharging sand from a river

The differences between the numerical and analytic solutions for the small breaking wave angle are much smaller than those for the larger breaking wave angles, because the assumption applied to obtain the equation (3.1) is violated.

The numerical results show that even if under actions of different breaking wave angles, the beach fill is always spreaded symmetrically towards both sides of initial beach fill. This can be interpreted by that the breaking wave angle as well as wave breaking height are assumed to be independent of $x$, therefore the distribution of alongshore sand is controlled by only shoreline configuration which has the symmetric shape with respect to the centre of the rectangle.

The maximum relative errors caused by the angles of 5, 15, and 30 degrees are 5.2 , 11.0 , and $38.0 \%$, respectively (see Table 1). That means the too large breaking wave angle will impair the analytic solution, overestimating the speed of the shoreline response.

\subsection{River discharging sand}

If a river mouth is small in comparison with the studied area, the sand discharge source from the river may be approximated by a point source. Assumption that a constant sand source $q_{0} \quad\left[\mathrm{~m}^{3} / \mathrm{s}\right]$ from the river is maintained at $x=x_{s}$, the initial shoreline is a straight line $y=y_{0}$. According to Carlaw and Jaeger (1959), the analytic solution may be expressed 
as [2].

$$
\begin{aligned}
& y(x, t)=\frac{q_{0}}{D_{C}+D_{B}}\left[\sqrt{\frac{t}{\pi \varepsilon}} \exp \left(\frac{-\left(x_{s}-x\right)^{2}}{4 \varepsilon t}\right)-\frac{\left|x-x_{s}\right|}{2 \varepsilon} \operatorname{erfc}\left(\frac{\left|x-x_{s}\right|}{2 \sqrt{\varepsilon t}}\right)\right], \\
& \text { for } t>0 \text { and }-\infty<x<\infty
\end{aligned}
$$

where the symbol erfc denotes the error function which is defined as [2]

$$
\operatorname{erfc}(z)=1-\frac{2}{\sqrt{\pi}} \int_{0}^{z} \exp \left(-\xi^{2}\right) d z
$$

In this example, $q_{0}$ was set to $0.02 \mathrm{~m}^{3} / \mathrm{s}$. The shorelines calculated by using the analytic solution (5.3) and numerical solutions are shown in Fig. 4.

In case of a small breaking wave angle, the numerical solution produces an almost identical shoreline (line 2) to the analytic (line 1). Sand from the river will be transported away from the river mouth much faster when the breaking wave angle approaches a large value, (line 4). The Fig. 4 shows that even if under actions of varying breaking wave angles, sand is symmetrically distributed towards both sides of the river mouth. This is explained as for the rectangle-shaped beach fill above. The details of wave parameters in the surf zone as well as river flow are ignored, thus, the breaking wave angle are only playing the role in as a diffusion coefficient.

The maximum relative errors caused by the angles of 5,15 , and 30 degrees are 0.7 , 7.5 , and $43.5 \%$, respectively (see Table 1 ).

\subsection{Groin interrupting sand transport}

Initially, the beach is in equilibrium (parallel to the x-axis). At time $t=0$ a thin groin is instantaneously placed at $x=0$, blocking all transport $(Q=0)$. Mathematically, by the equation (2.4), this boundary condition can be formulated as [2]

$$
\frac{\partial y}{\partial x}=\tan \alpha_{b}, \quad x=0 .
$$

This equation states that the shoreline at the groin is instant parallel to the wave crests. A groin interrupts the transport of sand alongshore, causing an accumulation on the updrift side and erosion on the downdrift side. The analytic solution describing the accumulation part on updrift side of the groin is [2]

$$
y(x, t)=2 \tan \alpha_{b}\left[\sqrt{\frac{\varepsilon t}{\pi}} \exp \left(-x^{2} / 4 \varepsilon t\right)-\frac{x}{2} \operatorname{erfc}\left(\frac{x}{2 \sqrt{\varepsilon t}}\right)\right] .
$$

In the numerical solution, the boundary condition at the groin which is totally blocking the transport of sand alongshore, is taken to be $Q=0$.

The shoreline positions calculated by analytic solution (5.5) and numerical solution are shown in Fig. 5. The comparison between the analytic and numerical solutions is only implemented on the updrift side, since the analytic solution on the downdrift side has not been considered in this paper. 
In this example, the wave diffraction at the groin and sand bypassing over the groin are not taken into account. However, the result obtained by numerical model shows a qualitative agreement with reality that accretion appeared on updrift side whereas erosion on downdrift side.

As expected, for the small angle, the numerical solution (line 2) gives an almost identical shoreline to the analytic (line 1). Like in the previous cases, a too large breaking wave angle will impair the analytic solution, overestimating the speed of shoreline response on updrift side. The figure 5 shows that the accumulation rate of sand on updrift side is much faster when the breaking wave angle increases.

The maximum relative errors caused by the angles of 5,15 , and 30 degrees are 4.4 , 7.2 , and $16.0 \%$, respectively (see Table 1 ). The error corresponding to the angle of 30 degrees is rather small in compare with two examples above.

\subsection{Sine-shaped beach}

The initial shoreline shape is treated by approximating its shape with a rhythmic form of a sine wave. The analytic solution to this case is found to be [4]

$$
\begin{gathered}
y_{(x, t)}=\sum_{n=1}^{\infty} a_{n} \exp \left[-\left(\frac{n \pi a}{L}\right)^{2} t\right] \sin \frac{n \pi x}{L}, \\
a_{n}=\frac{2}{L} \int_{0}^{L} A \sin \omega x \sin \frac{n \pi x}{L} d x, \quad n=1,2,3, \ldots,
\end{gathered}
$$

where $A$ is an initial amplitude of the beach wave, $\omega$ is an angle frequency of the beach wave.

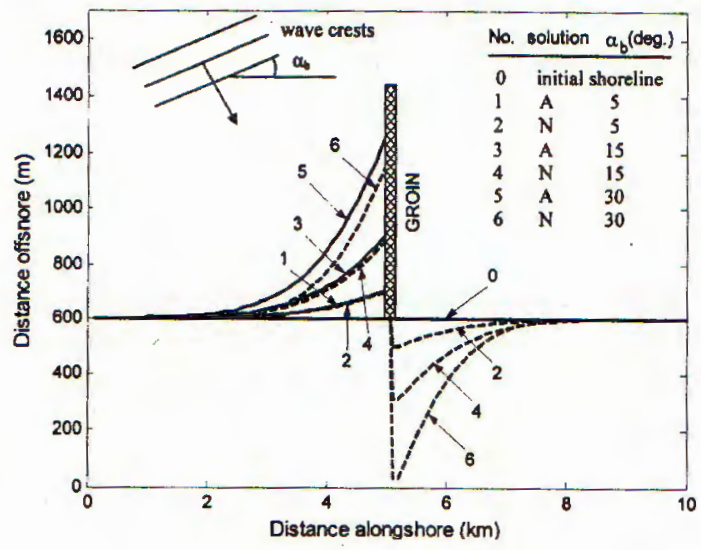

Fig. 5. Shoreline evolution at a groin

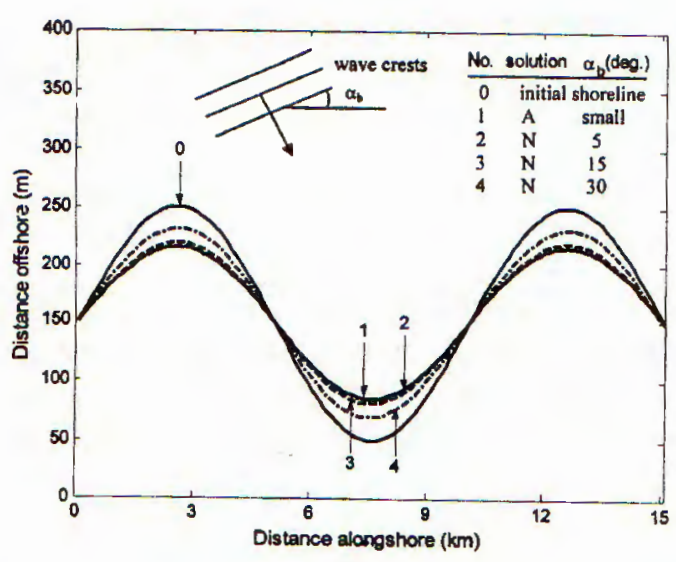

Fig. 6. Evolution of an initial sine-sharped shoreline

The shorelines calculated by the analytic solution (5.6) and numerical solution are shown in Fig. 6. Like in three previous examples, a small angle will gives a good agreement of the numerical with the analytic solution.

Under wave actions, the initial amplitude of the beach wave is attenuated with time but maintained its rhythmic character. 
The maximum relative errors caused by the angles of 5,15 , and 30 degrees are 1.5 , 11.4 , and $44.9 \%$, respectively (see Table 1 ).

The analytic solution (5.6) shows that when the time approaches to a great value, the amplitude of the beach wave will be reduced to zero, that means the beach wave becomes a straight line, and then the stable shoreline situation is established. Thus, under the action of waves having the constant parameters, the stable shoreline shape will be a straight line. This is reflected in Fig. 7.

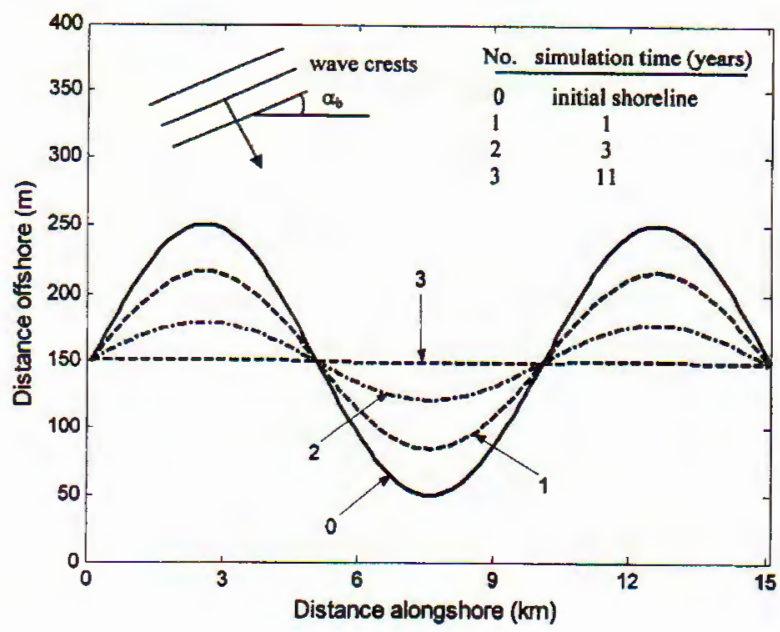

Fig. 7. Attenuation of an initial sin-sharped shoreline to straight shoreline

Table 1. Maximum relative error (\%) between numerical and analytic solutions for different breaking wave angles

\begin{tabular}{|l|c|c|c|}
\hline \multirow{2}{*}{\multicolumn{1}{|c|}{ Cases }} & \multicolumn{3}{|c|}{ Wave breaking angles, $\alpha_{b}$ (degrees) } \\
\cline { 2 - 4 } & $\alpha_{b}=5$ & $\alpha_{b}=15$ & $\alpha_{b}=30$ \\
\hline Rectangle-shaped beach fill & 5.2 & 11.0 & 38.0 \\
\hline River discharging sand & 0.7 & 7.5 & 43.5 \\
\hline Groin interupting sand transport & 4.4 & 7.2 & 16.0 \\
\hline Sine-shaped beach & 1.5 & 11.4 & 44.9 \\
\hline
\end{tabular}

\section{CONCLUSION}

The comparison between the analytic and numerical solutions for four different shoreline configurations under idealized wave condition are presented. The obtained results show that the agreement of the analytic with the numerical solution is only well if the breaking wave angle is small (kept within 15 degrees with maximum relative error of about $10 \%)$.

If the details of wave parameters near the structure as well as effects of river flow (in the case of river discharging sand) are ignored and the parameters of breaking waves are assumed to be independent of $x$ and $t$, the shoreline will have the symmetric shape with respect to the centre of the shoreline/structure configuration. 
If the breaking wave angle is too large, the analytic solutions will give an overestimation of the speed of shoreline response (except the case of river discharging sand). In the case of river discharging sand, the analytic solution will give an underestimation of the speed of shoreline response

The author acknowledge Prof. Pham Van Ninh and Prof. Tran Gia Lich for their useful comments.

The paper were partly supported by fundamental research project "Marine Hydrodynamics and Environment, Code 321501".

\section{REFERENCES}

1. Hans Hanson and Nicholas C. Kraus, GENESIS: Generalized Model for Simulating Shoreline Change, Report 1, Department of the Army, US Army Corps of Engineers, Washington, DC 20314-1000, December 1989.

2. Magnus Larson, Hans Hanson and Nicholas C. Kraus, Analytical Solutions of the Oneline Model of Shoreline Change, Final Report, Department of the Army, US Army Corps of Engineers, Washington, DC 20314-1000, October 1987.

3. Hans Hanson, Genersis - A Generalized Shoreline Change Numerical Model, Journal of Coastal Research 5 (1) (1989) 1-27.

4. A. G. Webster, Partial Differential Equations of Mathematical Physics, Dover Publications, INC. 1955

Received August 8, 2005

Revised April 18, 2006

\section{MộT SỐ KẾT QUẢ SO SÁNH GIŨ̃A NGHIỆM GIẢI TÍCH VÀ NGHIẸM SỐ VỀ SỰ BIẾN ĐỔI ĐƯờNG BỜ DỰA TRÊN MÔ HÌNH MộT DƯờNG}

Việc hiểu biết những đặc tính cơ bản của các hiện tượng vật lý phức tạp thường nhận được nhờ vào việc nghiên cứu các nghiệm giải tích được dẫn ra từ các bài toán đã được đơn giản hoá. Những nghiệm giải tích của mô hình biến đởi đường bờ đối với các dạng đường bờ đơn giản được dần ra dưới già thiết các điều kiện sóng được lý tưởng hoá. Cả nghiệm giải tích và mô hình số về sự biến đổi đường bờ đều dựa trên lý thuyết một đường (one-line). Bài báo trình bày một số kết quả so sánh giữa nghiệm giải tích và nghiệm số. 